\title{
Polyethylene glycol: A recyclable solvent system for the synthesis of benzimidazole derivatives using $\mathrm{CAN}$ as catalyst
}

\author{
MAZAAHIR KIDWAI*, ANWAR JAHAN and DIVYA BHATNAGAR \\ Green Chemistry Research Laboratory, Department of Chemistry, University of Delhi, Delhi 110007 \\ e-mail: kidwai.chemistry $@$ gmail.com
}

MS received 27 November 2009; revised 26 April 2010; accepted 19 May 2010

\begin{abstract}
Ceric ammonium nitrate (CAN) efficiently catalysed the synthesis of benzimidazole derivatives from $o$-phenylenediamine and aldehydes in PEG. This method provides a novel route for the synthesis of benzimidazoles in good yields with little catalyst loading. The recovery and the successful reutilization of the solvent system are also presented. Moreover, the easy set-up and purification tasks of this sustainable method make it appealing for bulk industry applications.
\end{abstract}

Keywords. Green synthesis; ceric ammonium nitrate; PEG; OPD; benzimidazoles; recyclability.

\section{Introduction}

Benzimidazole is a group of substances have found practical applications in organic synthesis ${ }^{1}$ and a significant structural element in medicinal chemistry owing to its diverse biological activities. ${ }^{2,3}$ Benzimidazoles are also being developed as DNA minor groove binding agents with antitumor activity. ${ }^{4}$ These act as ligand to transition-metal for modelling biological systems. ${ }^{5}$

Benzimidazoles have been synthesized by a number of method and using a variety of starting material. ${ }^{6-9}$ Literature survey revealed that the condensation of $o$-phenylenediamine with different substituted aldehydes in the presence of various transition metal-triflate salts such as $\mathrm{SC}(\mathrm{OTf})_{3}$ or $\mathrm{Yb}(\mathrm{OTf})_{3},{ }^{10,11}$ sulphamic acid, ${ }^{12} \mathrm{H}_{2} \mathrm{O}_{2}-\mathrm{HCl},{ }^{13} \mathrm{FeBr}_{3},{ }^{14}$ $\mathrm{KHSO}_{4}{ }^{15}$ and $\mathrm{HfCl}_{4}{ }^{16}$ afforded the title compound. Although these methods suffer from many drawbacks such as long reaction time, usage of expensive and corrosive reagent, high temperature with lesser yield products. In recent times ceric ammonium nitrate (CAN) has gained special attention ${ }^{17}$ and is extensively employed as a useful catalyst for $\mathrm{C}-\mathrm{C}$, $\mathrm{C}-\mathrm{N}, \mathrm{C}-\mathrm{S}$ and $\mathrm{C}-\mathrm{Se}$ bond forming reaction in synthetic organic chemistry ${ }^{18,19}$ as it is economically viable, water soluble with profound reactivity endowed with the reduction potential. ${ }^{20}$ In view of the

*For correspondence above usefulness, CAN became an effective catalyst towards the synthesis of benzimidazole derivatives.

In performing the majority of organic transformation, solvents play a critical role in mixing the ingredients to allow molecular interaction, like water ${ }^{21}$ and ionic-liquid ${ }^{22}$ as green solvent has also been documented, but ionic liquids safety is still debated and the reactions in water do not give good yields because of the hydrophobic nature of the organic reactants. Recently, polyethylene glycol is found to be an interesting recyclable and eco-friendly solvent system in synthetic chemistry for various organic transformations $^{23}$ with unique properties such as thermal stability, commercial availability and immiscibility with a number of organic solvents. In general, PEG is an inexpensive, non-toxic, completely non-halogenated and possesses low validity. Due to the low cost and easy handling of CAN and the green nature of recyclable $\mathrm{PEG}^{24}$ encouraged us to combine them together and used their utility for the synthesis of benzimidazoles.

\section{Experimental}

\subsection{Materials and method}

All chemicals were purchased from sigma-Aldrich and Lancaster and were used without further purification. All reactions and purity of 2-aryl benzimidazole derivatives were monitored by thin layer chromatography (TLC) using aluminium plates 
coated with silica gel (Merck) using 20\% ethylacetate, $80 \%$ pertroleum ether as an eluent. The isolated products were further purified by column-chromatography using silica gel (100-200 mesh) purchased from Sisco Research Laboratories Pvt. Ltd. Mumbai, India and purified products were recrystallized. ${ }^{1} \mathrm{H}$ NMR spectra were recorded on a Bruker Avance Spectrospin $300(300 \mathrm{MHz})$. All NMR samples were run in $\mathrm{CDCl}_{3}$ and chemical shifts are expressed as $\delta$ relative to internal TMS. IR spectra were obtained on Perkin Elmer FT-IR spectrometer spectrum-2000 using potassium bromide pellets. ESI-MS mass spectra were recorded on a waters LCT Micromass. The temperature of the reaction mixture was measured through a non-contact infrared thermometer (AZ, Mini Gun Type, Model 8868).

\subsection{General procedure for the synthesis of benzimidazoles}

In a $50 \mathrm{ml}$ round bottom flask, a mixture of $o$ phenyldiamine (OPD) (1 mmol) and aldehydes $(1 \mathrm{mmol})$ in polyethylene glycol $(5 \mathrm{ml})$ were mixed and stirred in the presence of ceric ammonium nitrate $(\mathrm{CAN})$ catalyst $(5 \mathrm{~mol} \%)$ at $50^{\circ} \mathrm{C}$ for $2 \mathrm{~h}$. The progress of reaction mixture was monitored by TLC. On completion of reaction, the reaction mixture was cooled in dry ice-acetone bath to precipitate the PEG 400 and extracted with ether (PEG being insoluble in ether). The reaction mixture was filtered in order to recover the catalyst and filtrate was washed with $\mathrm{H}_{2} \mathrm{O}$ and dried. The crude product was purified by silica-gel column chromatography using $15 \%$ ethylacetate as an eluent to yield the 2-aryl benzimidazoles. The recovered PEG can be reused for further reactions. All the known compounds were characterized by comparing their physical (MPs) ${ }^{25-28}$ and spectral data (IR, ${ }^{1} \mathrm{H}$ NMR and ${ }^{13} \mathrm{C}$ NMR) with those of reported compounds (see supplementary information for details, www.ias.ac.in/ chemsci).

\section{Results and discussion}

In continuation of our efforts on developing green methodologies for biologically active organic compounds ${ }^{29}$ we report here a CAN catalysed procedure for the synthesis of benzimidazole derivatives in PEG at $50^{\circ} \mathrm{C}$.

Initially, a blank reaction was carried out using 1 equiv. each of $o$-phenylenediamine and benzalde- hyde. These were stirred at ambient temperature in ethanol for $32 \mathrm{~h}$ and only $35 \%$ of the expected product was obtained. The same reaction was then carried out using PEG as the reaction medium under similar conditions. Surprisingly, a significant improvement was observed and the yield of product was dramatically increased to $67 \%$ for $8 \mathrm{~h}$. Further to improve the yield and also to explore the catalytic activity of CAN the reaction was carried out with same amount of reactants in PEG $(5 \mathrm{~mL})$ were stirred at $50{ }^{\circ} \mathrm{C}$ in the presence of $2 \mathrm{~mol} \%$ of CAN for $4 \mathrm{~h}$, a good improvement was observed and the reaction yielded $95 \%$ benzimidazole (scheme 1).

With this optimistic result in hand, we further investigated the best reaction condition by using different amounts of CAN. An increase in the quantity of CAN from $2 \mathrm{~mol} \%$ to $5 \mathrm{~mol} \%$, not only decreased the reaction time from $4 \mathrm{~h}$ to $2 \mathrm{~h}$ but also increased the product yield from 95 to $98 \%$. This showed that the catalyst concentration plays a major role in optimization of the product yield. Although the use of

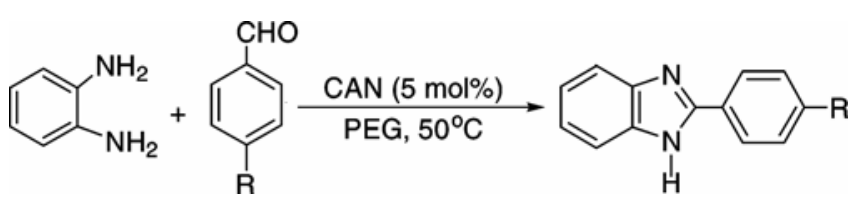

Scheme 1.

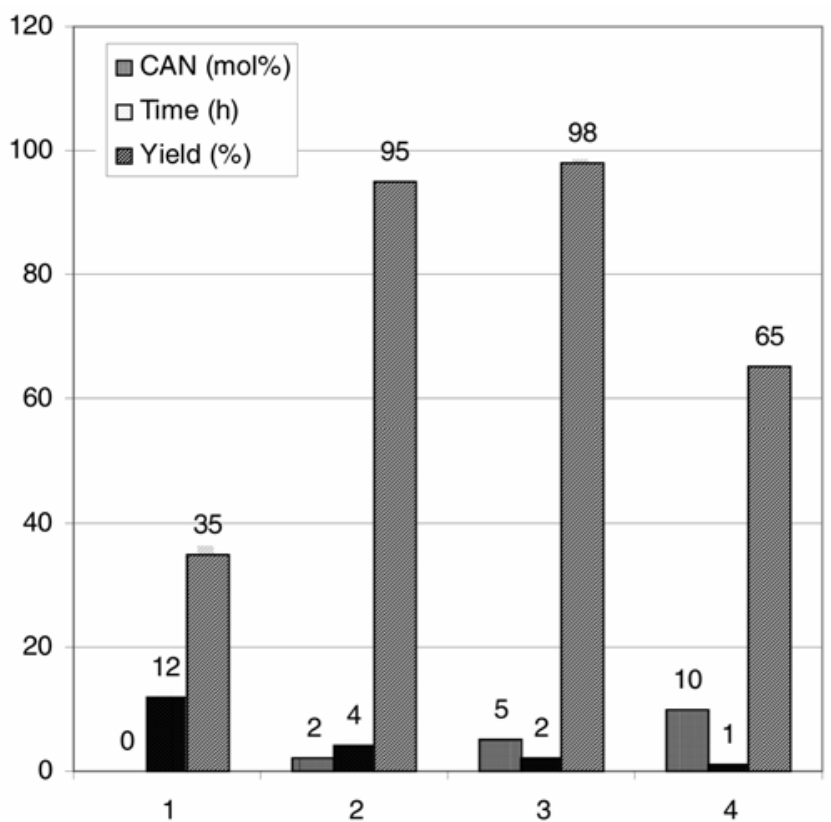

Figure 1. Catalytic activity evaluation for benzimidazoles. Reaction conditions: $o$-phenylenediamine $(1 \mathrm{mmol})$, benzaldehyde ( $1 \mathrm{mmol}$ ); solvent PEG 400 ; temperature $50^{\circ} \mathrm{C}$. Isolated yields. 
Table 1. Synthesis of 2-phenyl benzimidazole derivatives by using CAN-PEG system. ${ }^{\mathrm{a}}$

\begin{tabular}{|c|c|c|c|c|}
\hline Entry & Aldehyde & Product & Time (h) & Yield (\%) \\
\hline 1 & & & 2 & 98 \\
\hline 2 & & & 1.5 & 94 \\
\hline 3 & & & 1.5 & 94 \\
\hline 4 & & & 2.5 & 92 \\
\hline 5 & & & 3 & 90 \\
\hline 6 & & & 2 & 92 \\
\hline 7 & & & 2 & 90 \\
\hline 8 & & & 1.5 & 95 \\
\hline 9 & & & 1.5 & 96 \\
\hline 10 & & & 2 & 94 \\
\hline 11 & & & 3 & 90 \\
\hline 12 & & & 2 & 95 \\
\hline 13 & & & 2 & 94 \\
\hline 14 & & & $2 \cdot 5$ & 90 \\
\hline 15 & & & 2.5 & 91 \\
\hline
\end{tabular}

${ }^{a}$ Reaction conditions: $o$-phenylenediamine $(1 \mathrm{mmol})$, aldehydes $(1 \mathrm{mmol})$, CAN $(5 \mathrm{~mol} \%)$; solvent PEG 400; temperature $50^{\circ} \mathrm{C}$

${ }^{\mathrm{b}}$ Isolated yields 
$10 \mathrm{~mol} \%$ of CAN permitted the reaction time to be decreased to $1 \mathrm{~h}$, the yield unexpectedly decreased to $65 \%$. A possible explanation for the low product yields is that the starting material or the product may

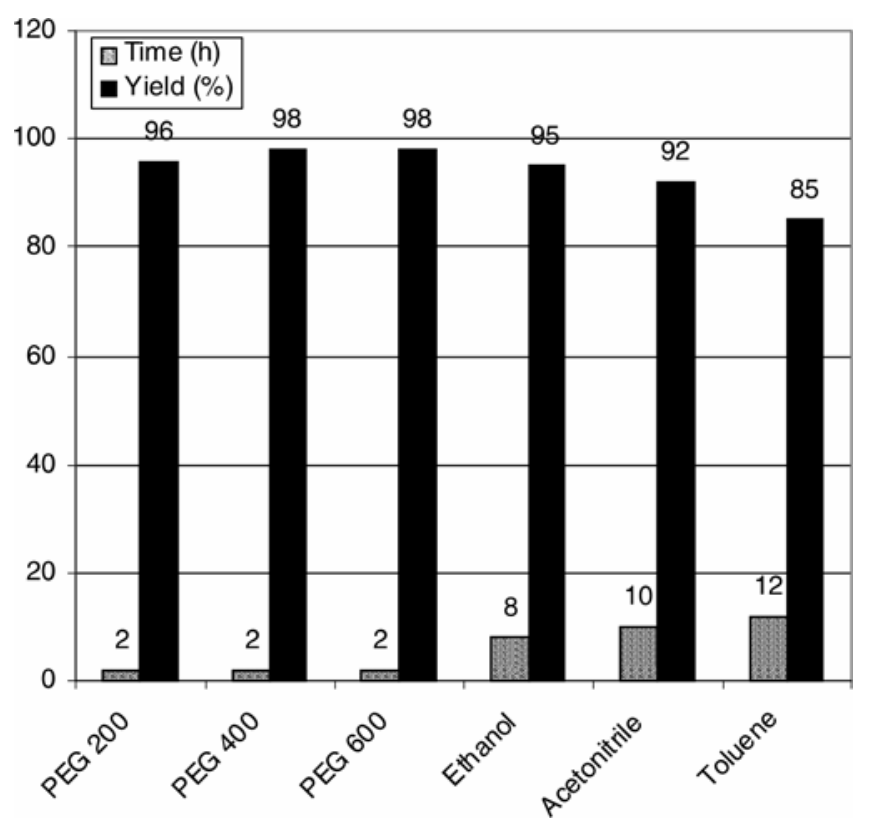

Figure 2. CAN catalyze Benzimidazoles reaction in various solvents. Reaction conditions: $o$-phenylenediamine (1 mmol), benzaldehyde $(1 \mathrm{mmol})$; solvent PEG 400 ; temperature $50^{\circ} \mathrm{C}$. Isolated yields.

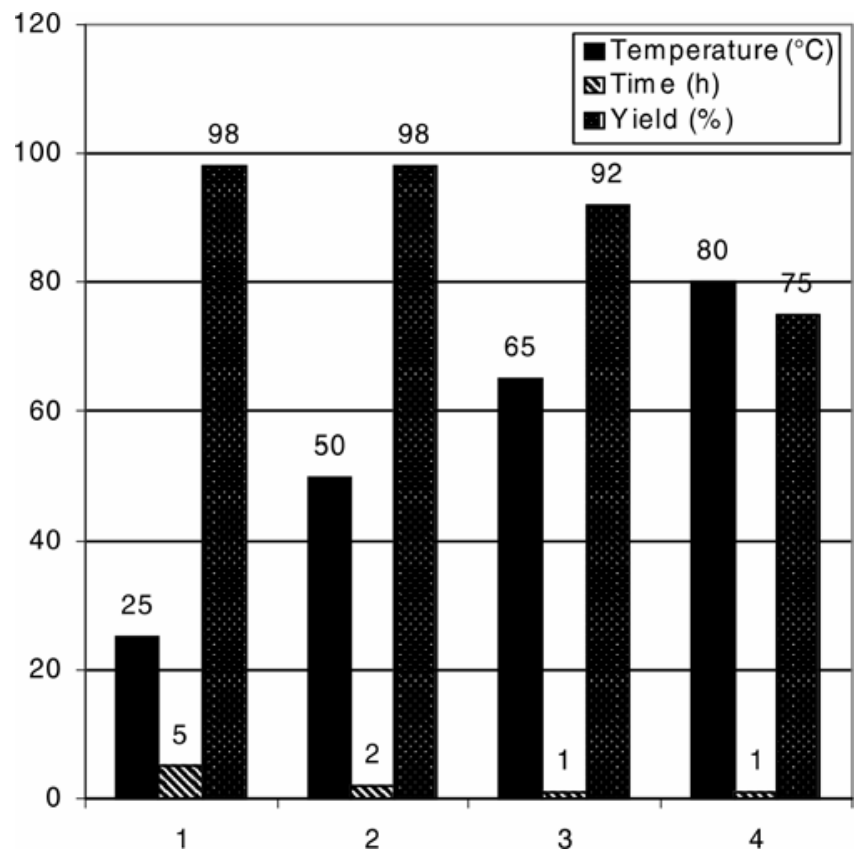

Figure 3. Effect of Temperature. Reaction conditions: $o$-phenylenediamine $(1 \mathrm{mmol})$, benzaldehyde $(1 \mathrm{mmol})$, CAN ( 5 mol\%); solvent PEG 400 ; temperature $50^{\circ} \mathrm{C}$. Isolated yields. have been destroyed during the reaction when excess amount $(10 \mathrm{~mol} \%)$ of CAN was used in the reaction. It appears that a concentration of $5 \mathrm{~mol} \%$ of CAN is the suitable choice for an optimum yield of benzimidazoles (figure 1).

In order to study the generality of this procedure, the applicability of the PEG with CAN system was then examined for the reaction of a series of aromatic aldehydes with $o$-phenylenediamine under the optimized reaction conditions (table 1). As shown, a variety of substituted aromatic aldehydes, bearing either electron-donating or electron-withdrawing substituents, afforded the products in excellent yields and high purities. In addition, heterocyclic aldehydes could also be used for efficient preparation of various heterocyclic-benzimidazoles (table 1, entry 14 and 15). It was interesting to observe the remarkable stability of a variety of functional groups such as ether, nitro, hydroxyl, halides, and formyl under the reaction conditions.

The nature of reaction media has an important role in the synthesis of benzimidazoles in the presence of CAN (5 mol\%). Almost all solvents afforded products in excellent yield with a variation in reaction time. Therefore we used only PEG as a solvent because it is recyclable, non-toxic and thermally stable (figure 2).

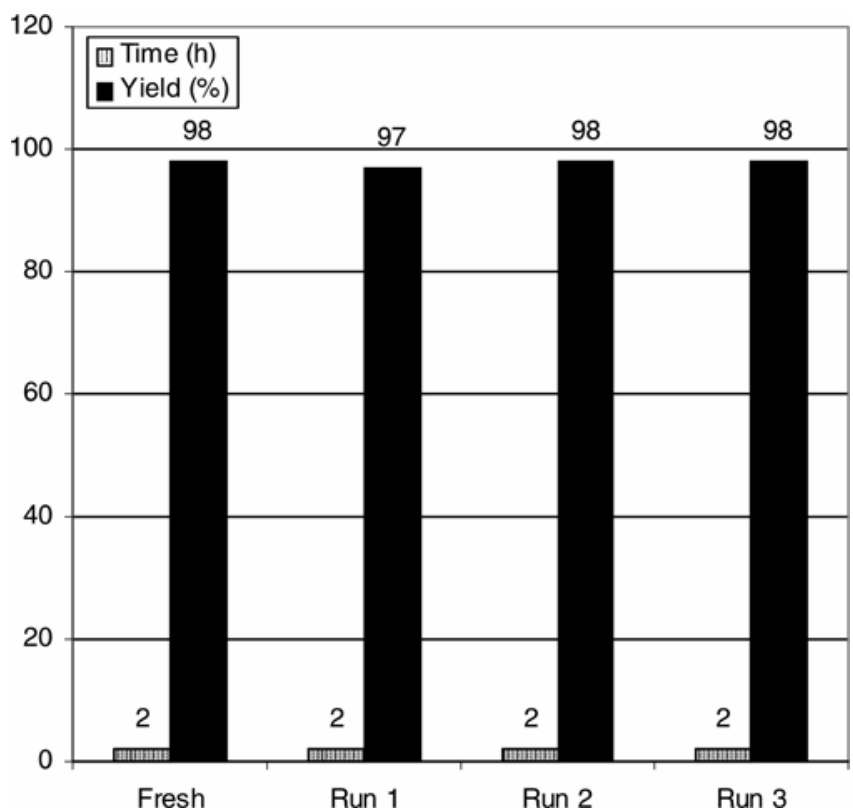

Figure 4. Recycling yields. Reaction conditions: $o$-phenylenediamine $(1 \mathrm{mmol})$, aldehyde $(1 \mathrm{mmol}), \mathrm{CAN}$ ( $5 \mathrm{~mol} \%$ ); solvent $\mathrm{PEG} 400$; temperature $50^{\circ} \mathrm{C}$. Isolated yields. 


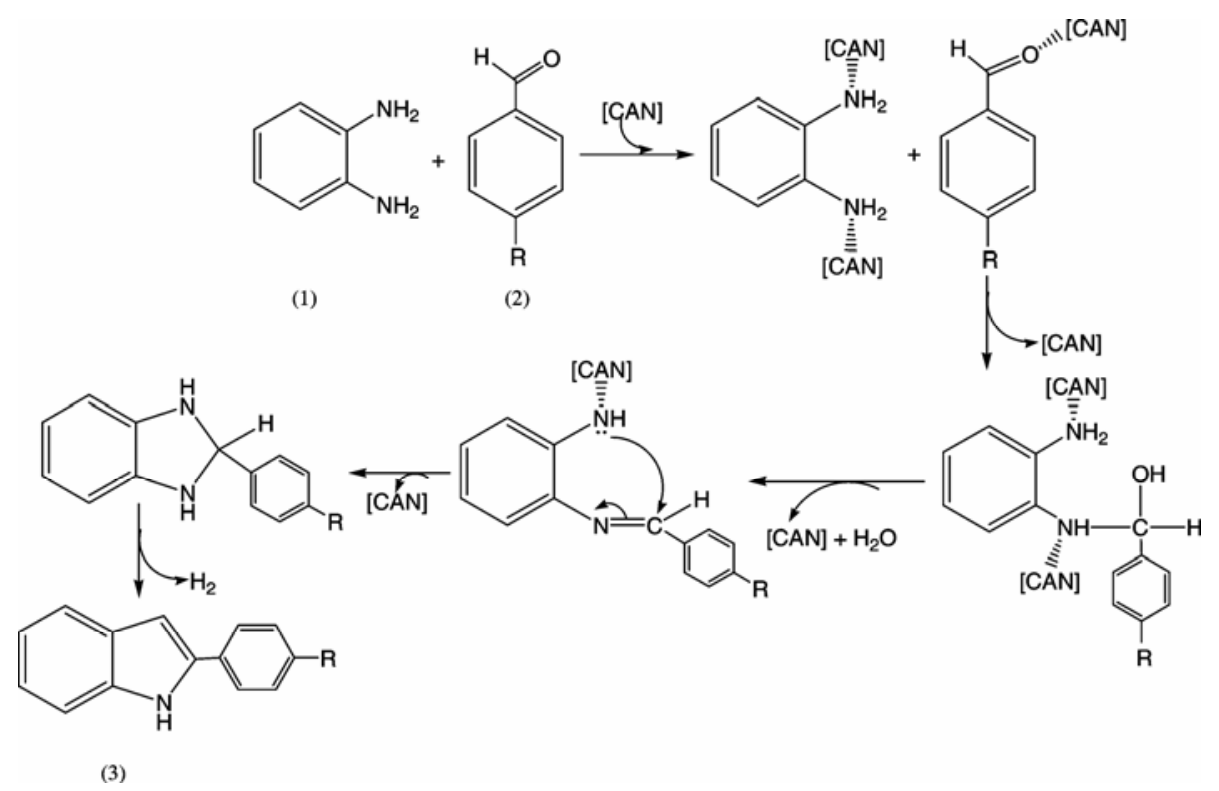

Scheme 2.

The effect of temperature was also studied. Faster reactions occurred on raising the temperature but the yield of product decreased at higher temperature possibly because one of the reactants (aldehydes) oxidizes at high temperature in presence of CAN (figure 3).

In order to prove that the use of polyethylene glycol as solvent is also practical, it was recycled with minimum loss and decomposition. Since polyethylene glycol is immiscible with solvent ether, the desired product may be extracted with it and remaining PEG phase may be used. The solvent phase was recycled with no change in reactivity for three cycles but approximately 5\% weight loss of PEG was observed from cycle to cycle (figure 4).

A plausible mechanism as supported by the literature $^{30}$ has been reported (scheme 2). Overall this methodology offers the competitive advantages of recyclability of the solvents which could be used without further purification and without any additions. It also requires less loading of the catalyst and has broad substrate applicability with ease and improved yields.

\section{Conclusion}

In conclusion, the PEG has been employed as a novel, mild, and highly efficient solvent system for the convenient preparation of benzimidazoles in excellent yields from $o$-phenyldiamine and a wide variety of aryl aldehydes using CAN as catalyst. In addition low cost, recyclable solvent system and ready availability of catalyst, an environmentally benign procedure makes this methodology a useful contribution to the existing procedures available for the synthesis of benzimidazole derivatives.

\section{Acknowledgement}

A J and D B thank University Grants Commission (UGC), New Delhi for fellowship.

\section{References}

1. Bai Y, Lu J, Shi Z and Yang B 2001 Synlett. 544

2. He Y, Yang J, Wu B, Risen L and Swayze E E 2004 Bioorg. Med. Chem. Lett. 141217

3. Sharma S, Gangal S and Rauf A E 2009 Eur. J. Med. Chem. 441751

4. Tanious F A, Hamelberg D, Bailly C, Czarny A, Boykin D W and Wilson W D $2004 \mathrm{~J}$. Am. Chem. Soc. 126143

5. Oren I Y, Yalcin I, Sener E A and Ucarturk N 2004 Eur. J. Med. Chem. 39291

6. Grimmet M R in (eds) Katritzky A R C W Rees 1984 Hetero. Chem. 457

7. Fairley $\mathrm{T}$ A, Tidwell R R, Donkor I, Naiman N A, Ohemeng K A, Lombardy R J, Bentley J A and Cory M 1993 J Med. Chem. 361746

8. Czarny A, Wilson W D and Boykin D W 1996 J. Heterocyclic Chem. 331393

9. Raut C N, Mane R B, Bagul S M, Janrao R A and Mahulikar P P 2009 Arkivoc xi 105 
10. Nagata K, Itoh T, Ishikawa H and Ohsawa A 2003 Heterocycles $\mathbf{6 1} 93$

11. Curini M, Epifano F, Montanari F, Rosati O and Taccone S 2004 Synlett. 1832

12. Chakrabarty M, Karmakar S, Ajanta M, Arima S and Harigaya Y 2006 Heterocycles 68967

13. Bahrami K, Khodaei M M and Kavianinia I 2007 Synthesis 4547

14. Aliyan H, Fazaeli R, Fazaeli N, Mssah A R, Naghash H J, Alizadeh M and Emami G 2009 Heteroatom Chem. 20202

15. Ma H, Wang $\mathrm{Y}$ and Wang J 2006 Heterocycles 68 1669

16. Zhang Z H, Yin L and Wang Y M 2007 Catal. Commun. 81126

17. Dhakshinamoorthy A and Pitchumani K 2009 Catal. Commun. 10872

18. Wang $\mathrm{L}$, Jing $\mathrm{H}, \mathrm{Bu} \mathrm{X}$, Chang $\mathrm{T}$, Jin $\mathrm{L}$ and Liang $\mathrm{Y}$ 2007 Catal. Commun. 880

19. Nair V and Deepthi A 2007 Chem. Rev. 1071862

20. Haldar P and Ray J K 2008 Tetrahedron Lett. 493659
21. Muthusamy S and Srinivasan P 2009 Tetrahedron Lett. 501331

22. Sheldon R 2001 Chem. Commun. 2399

23. Sun D and Zhai H 2007 Catal. Commun. 81027

24. Kidwai M, Bhatnagar D, Mishra N K and Bansal V 2008 Catal. Commun. 92547

25. Sharghi H, Hosseini-Sarvari M and Moeini F 2008 Can. J. Chem. 861044

26. Mobinikhaledi A, Forughifar N, Zendehdel M and Jabbarpour M 2008 Syn. Reac. Inorg. Metal-Org. Nano-Metal Chem. 38390

27. Navarrete-Vazquez G, Moreno-Diaz H, AguirreCrespo F, Leon-Rivera I, Villalobos-Molina R, Munoz-Muniz O and Estrada-Soto S 2006 Bioorg. Med. Chem. Lett. 164169

28. Alloum A B, Bougrin K and Soufiaoui M 2003 Tetrahedron Lett. 445935

29. Kidwai M, Bansal V and Mothsra P $2007 \mathrm{~J}$. Mol. Catal. A: Chem. 26643

30. Shelke K F, Sapkal S B and Shingare M S 2009 Chin. Chem. Lett. 20283 